DOI: 10.20472/IAC.2020.053.016

THOMAS SIMON

Johns Hopkins University, China

\title{
INDUSTRIAL DISASTER AND CORPORATE IRRESPONSIBILITY: RANA PLAZA DEBACLE
}

\begin{abstract}
:
Although the indirect (Bilateral Investment Treaties (BITs), arbitral decisions, and Corporate Social Responsibility (CSR)) and direct (Accord, Alliance) responses to the Rana Plaza and similar disasters, eventually, made improvements for workers in the Ready Made Garment (RMG) industry, they ultimately have proven unsatisfactory because they do not challenge the fundamental and structural impediment, namely, the dominance of the economic investment regime over human rights. A new paradigm anchored in health law creates an entirely new and fresh framework for rethinking the problems. Within that health paradigm, a ban on workplace smoking can provide a wedge for opening the door for workers to begin to make fundamental changes in their well-being. Health, for far too long, has remained at the bottom of the human rights hierarchy. Putting health first actually makes it more likely that safety issues will be adequately addressed in a systematic and meaningful way. Giving priority to health rights creates opportunities to radically change the terms of the debates. Using a ban on workplace smoking provides a wedge and the first step to effecting this radical transformation.
\end{abstract}

\section{Keywords:}

corporate social responsibility, bilateral investment treaties, industrial disasters, right to health, workers rights

JEL Classification: K32, K31, K33 